\title{
Dietary Probucol Preserves Endothelial Function in Cholesterol-fed Rabbits by Limiting Vascular Oxidative Stress and Superoxide Generation
}

John F. Keaney, Jr., Aiming Xu, David Cunningham, Terence Jackson, Balz Frei, and Joseph A. Vita

Evans Memorial Department of Medicine and Whitaker Cardiovascular Institute, Boston University Medical Center, Boston, Massachusetts 02118

\begin{abstract}
Excess vascular oxidative stress and the local formation of oxidized LDL (ox-LDL) have been implicated in the development of impaired endothelium-dependent arterial relaxation in hypercholesterolemia and atherosclerosis. Dietary antioxidants limit LDL oxidation in vitro and treatment of cholesterol-fed rabbits with dietary antioxidants preserves endothelium-derived relaxing factor (EDRF) action. To investigate the mechanism(s) responsible for these observations, we examined EDRF action, vascular oxidative stress, and antioxidant protection in male New Zealand White rabbits using four dietary treatments. Animals consumed standard chow (chow group) or chow supplemented with: (a) $0.5 \%$ cholesterol ( $0.5 \%$ cholesterol group); (b) $1 \%$ cholesterol (1\% cholesterol group); or (c) 1\% cholesterol and $1 \%$ probucol (probucol group). After $28 \mathrm{~d}$ of dietary treatment, segments of thoracic aorta from the 0.5 and $1 \%$ cholesterol groups demonstrated impairment of acetylcholine-mediated endothelium-dependent arterial relaxation compared to chow-fed animals $(57 \pm 11 \%$ and $45 \pm 9 \%$ vs $78 \pm 3 \%$, respectively; $P<0.05)$. In contrast, vessels from the probucol group demonstrated normal relaxation to acetylcholine $(83 \pm 5 \%)$. Plasma cholesterol levels and the extent of atherosclerosis were similar among all cholesterol-fed groups. Probucol treatment was associated a threefold increase in LDL resistance to copper-induced oxidative modification $(P<0.05)$ and a reduction in tissue lipid peroxidation (as assessed by thiobarbituric acid-reactive substances; $P$ $<0.05$ ) compared to animals fed cholesterol alone. Most importantly, both of these changes were strongly correlated with preserved EDRF action. Moreover, cholesterol feeding was associated with a dose-dependent increase in vascular superoxide generation and lysophosphatidylcholine content, both of which were prevented by probucol treatment. From these findings, we conclude that probucol, a lipid-soluble antioxidant, preserves EDRF action in cholesterol-fed rabbits in association with limiting vascular oxidative stress and superoxide generation. (J. Clin. Invest. 1995. 95:2520-2529.) Key words: cholesterol $\bullet$ probucol $\bullet$ oxidation • endotheliumderived relaxing factor $\bullet$ antioxidants
\end{abstract}

Address correspondence to John F. Keaney, Jr., Whitaker Cardiovascular Institute, Boston University School of Medicine, 80 East Concord Street, W507, Boston, MA 02118. FAX: 617-638-4066.

Received for publication 7 November 1994 and in revised form 12 January 1995.

J. Clin. Invest.

(c) The American Society for Clinical Investigation, Inc.

$0021-9738 / 95 / 06 / 2520 / 10 \quad \$ 2.00$

Volume 95, June 1995, 2520-2529

\section{Introduction}

The vascular endothelium is important in the maintenance of vascular homeostasis. Normally, the vascular endothelium prevents inappropriate vasospasm and platelet adhesion to the vascular surface through the production of numerous paracrine factors (for review see reference 1). Principal among these mediators of vascular homeostasis is endothelium-derived relaxing factor (EDRF), ${ }^{1}$ an endothelial product that has been identified as nitric oxide (NO) (2), or a closely related redoxactivated form of NO (3). This endothelial product relaxes vascular smooth muscle and prevents platelet adhesion to the endothelial surface through a cyclic $3^{\prime}, 5^{\prime}$-guanosine monophosphate-mediated mechanism $(4,5)$. Abnormalities in EDRF action have been described in association with known risk factors for acute vascular events including hypercholesterolemia (6) and atherosclerosis (7). These abnormalities develop early in the course of vascular disease $(6,8)$ and may participate in the development of clinically significant vascular events.

There are now several lines of evidence linking excess vascular oxidative stress to the impairment of EDRF action associated with hypercholesterolemia and atherosclerosis. Early in atherogenesis, LDL becomes entrapped in the subendothelial space of lesion-prone arterial sites where it is subject to oxidation by endothelial cells (9), smooth muscle cells (10), and resident monocyte/macrophages (11). Oxidized LDL (oxLDL) inhibits receptor-mediated endothelium-dependent arterial relaxation (12) and signal transduction (13). Moreover, ox-LDL is cytotoxic (14) and degrades EDRF directly (15), further promoting abnormal EDRF action.

Other sources of vascular oxidative stress may also contribute to impaired EDRF action. EDRF is readily inactivated by superoxide (16) and the action of EDRF is dependent upon intact endothelial SOD activity (17). In particular, arteries derived from cholesterol-fed rabbits produce excess superoxide (18) and the administration of SOD to atherosclerotic rabbits improves EDRF action $(19,20)$. Thus, there is considerable evidence indicating that excess vascular oxidative stress contributes to impaired EDRF action in experimental hypercholesterolemia and atherosclerosis.

Developing evidence also suggests that improved vascular antioxidant defenses may limit abnormalities of endotheliumdependent arterial relaxation associated with hypercholesterolemia and atherosclerosis. Atherosclerotic rabbits treated chronically with probucol, a cholesterol-lowering drug with potent antioxidant properties (21), exhibit preserved endothelium-de-

1. Abbreviations used in this paper: DDC, diethyldithiocarbamate; EDRF, endothelium-derived relaxing factor; lysoPC, lysophosphatidylcholine; MDA, malondialdehyde; NO, nitric oxide; ox-LDL, oxidized LDL; PC, phosphatidylcholine; PSS, physiologic saline solution; TBARS, thiobarbituric acid-reactive substances. 
pendent arterial relaxation compared to animals fed cholesterol alone (22). Similarly, cholesterol-fed rabbits treated with other lipid-soluble antioxidants such as $\alpha$-tocopherol $(23,24)$ and $\beta$ carotene (23) demonstrate preserved EDRF action in association with incorporation of these agents into vascular tissue (23). Similar findings have been reported with cholesterol-fed rats, animals that do not typically demonstrate impaired endothelium-dependent arterial relaxation unless they are simultaneously deficient in selenium and $\alpha$-tocopherol (25).

Despite the demonstration that some antioxidants preserve endothelium-dependent arterial relaxation in hypercholesterolemia and atherosclerosis, the precise mechanism(s) that underlie this phenomenon are not well defined. Thus, we sought to examine the mechanism ( $s$ ) by which enhanced vascular antioxidant protection preserves endothelium-dependent arterial relaxation in the cholesterol-fed rabbit model using probucol.

\section{Methods}

Materials. Ketamine hydrochloride was purchased from Aveco Co., Inc. (Fort Dodge, IA) and sodium pentobarbital was obtained from Anthony Products Co. (Arcadia, CA). Sodium nitroprusside was obtained from Abbott Laboratories (North Chicago, IL). Vacutainer ${ }^{\mathrm{TM}}$ tubes were purchased from Becton-Dickinson and Co. (Rutherford, NJ) and Chelex 100 resin (100-200 mesh) was from Bio-Rad Laboratories, Hercules, CA. Porcine intestinal mucosal heparin was purchased from ElkinsSinn, Inc. (Cherry Hill, NJ). Probucol was a gift of Marion-Merrell Dow, Inc. (Cincinnati, $\mathrm{OH}$ ) and xanthine oxidase was obtained from Boehringer Mannheim Biochemicals, (Indianapolis, IN). Calcium ionophore (A23187), acetylcholine hydrochloride, norepinephrine, potassium bromide $(\mathrm{KBr})$, cupric chloride $\left(\mathrm{CuCl}_{2}\right)$, Lowry protein assay kits (P5656), Hepes, and all other compounds were purchased from Sigma Chemical Co. (St. Louis, MO).

Physiologic salt solution (PSS) contained $118.3 \mathrm{mM} \mathrm{NaCl}, 4.7 \mathrm{mM}$ $\mathrm{KCl}, 2.5 \mathrm{mM} \mathrm{CaCl}_{2}, 1.2 \mathrm{mM} \mathrm{MgSO}{ }_{4}, 1.2 \mathrm{mM} \mathrm{KH} \mathrm{PO}_{4}, 25 \mathrm{mM}$ $\mathrm{NaHCO}_{3}, 11.1 \mathrm{mM}$ glucose, and $0.026 \mathrm{mM} \mathrm{Na} \mathrm{EDT}_{2}$. PBS consisted of $10 \mathrm{mM} \mathrm{NaP}, 0.15 \mathrm{M} \mathrm{NaCl}, \mathrm{pH}$ 7.4. Reagents used for LDL experiments were prepared with Chelex-treated, double-distilled, deionized water to prevent premature LDL oxidation catalyzed by trace amounts of transition metal ions. A23187 was prepared and diluted in 2\% DMSO while all other reagents were prepared with distilled water.

Animal subjects. 64 male New Zealand White rabbits $(2.6-3.8 \mathrm{~kg})$ were exposed to dietary treatment for a period of $28 \mathrm{~d}$. 16 of these animals were fed standard rabbit chow and served as the control group. 48 animals were fed a chow diet containing the following supplements ( $n=16$ per group): $(a) 0.5 \%(\mathrm{wt} / \mathrm{wt})$ cholesterol, $(b) 1 \%(\mathrm{wt} / \mathrm{wt})$ cholesterol; and (c) $1 \%$ cholesterol with $1 \%$ (wt/wt) probucol. Cholesterol chow was prepared by dissolving pure cholesterol (Sigma Chemical Co.) in ether and spraying the appropriate amount over standard chow. Animals consumed chow and water ad libitum. Blood was obtained in Vacutainer tubes $\left(4.5 \mathrm{mg} \mathrm{Na}{ }_{2}\right.$ EDTA $/ 3 \mathrm{ml}$ ) before dietary treatment and at the time of death. Plasma was prepared and stored at $-70^{\circ} \mathrm{C}$ for subsequent assay of plasma cholesterol, triglyceride, and antioxidant levels. Plasma total cholesterol (26) and triglycerides (27) were quantified using enzymatic methods.

In vitro assay of vascular function. Rabbits were killed with pentobarbital $(120 \mathrm{mg} / \mathrm{kg})$ via a marginal ear vein, the thoracic aorta excised, and vessel segments suspended in organ chambers as previously described (23). Endothelial control of vascular tone was assayed by the addition of the muscarinic agonist acetylcholine (final concentration $\left.10^{-9}-10^{-5} \mathrm{M}\right)$ and the calcium ionophore A23187 $\left(10^{-9.5}-10^{-6} \mathrm{M}\right)$, while smooth muscle cell vasodilator function was assayed using sodium nitroprusside $\left(10^{-9}-10^{-5} \mathrm{M}\right)$.

Plasma, $L D L$, and aortic antioxidant content. Plasma and aortic probucol content was determined by the method of Mao and colleagues (28) using HPLC with a 25-cm LC-18 column (Supelco Inc., Bellfonte,
PA) and ultraviolet detection ( 1050 series chemstation; Hewlett-Packard Co., Palo Alto, CA). Plasma $\alpha$-tocopherol content was determined as described (29) after saponification for $30 \mathrm{~min}$ with $10 \mathrm{~N} \mathrm{KOH}$ in the presence of $25 \%$ ascorbate. For aortic $\alpha$-tocopherol content, tissue samples $(0.1-0.35 \mathrm{~g})$ were prepared as described (23) and subjected to reverse-phase HPLC (29) using an amperometric electrochemical detector (model 1049A; Hewlett-Packard Co.) at an applied potential of 0.6 V. Calibration of the HPLC system was performed daily using fresh solutions of $d, 1-\alpha$-tocopherol in ethanol.

For LDL antioxidant content, a $125-\mu 1$ sample containing $0.1 \mathrm{mg}$ LDL protein in PBS was extracted with $125 \mu \mathrm{l}$ methanol and $2.5 \mathrm{ml}$ hexane. The hexane phase $(2.0 \mathrm{ml})$ was dried under nitrogen, resuspended in ethanol, and subjected to reverse-phase HPLC with electrochemical detection as described above except that the applied potential was $1.0 \mathrm{~V}$. Calibration of the HPLC system was performed daily using fresh solutions of $d, 1-\alpha$-tocopherol and probucol in ethanol.

$L D L$ oxidation studies. The isolation and oxidation of LDL were performed as described previously (30). Standard incubation of LDL for susceptibility to oxidation was performed at a concentration of 0.1 $\mathrm{mg} \mathrm{LDL}$ protein $/ \mathrm{ml}$ in the presence of $1.25 \mu \mathrm{M} \mathrm{CuCl}_{2}$ at $37^{\circ} \mathrm{C}$. Lipid peroxidation was determined by assay of sample absorbance at $234 \mathrm{~nm}$ (diene conjugation) in 10-min intervals using a spectrophotometer (U2000; Hitachi Instruments Inc., San Jose, CA) equipped with a thermostatic six-cell holder. LDL susceptibility to lipid peroxidation was quantified by the lag phase duration before the propagation phase of diene conjugation (31).

Measurement of vascular thiobarbituric acid-reactive substances (TBARS). Segments of thoracic aorta $(3 \mathrm{~mm})$ not used for vascular function studies were homogenized in $1 \mathrm{ml}$ PBS containing $50 \mu \mathrm{M}$ butylated hydroxytoluene (BHT) and $0.1 \mathrm{mM}$ diethylenetriamene pentaacetic acid (DTPA). An aliquot of the homogenate $(0.5 \mathrm{ml})$ was incubated with equal volumes of $2.8 \%(\mathrm{wt} / \mathrm{vol}) \mathrm{TCA}$ and $1 \%(\mathrm{wt} / \mathrm{vol})$ thiobarbituric acid (in $50 \mathrm{mM} \mathrm{NaOH}$ ) for $10 \mathrm{~min}$ at $100^{\circ} \mathrm{C}$, extracted with $2.0 \mathrm{ml} n$-butanol, and the extract absorbance determined at 532 $\mathrm{nm}$. TBARS were determined from a standard curve prepared with 1,1,3,3-tetramethoxypropane. The remaining homogenate was incubated with $50 \mu \mathrm{l} 10 \mathrm{~N} \mathrm{NaOH}$ at $100^{\circ} \mathrm{C}$, neutralized with $\mathrm{HCl}$, and the protein content determined (32). TBARS are expressed as nanomoles of malondialdehyde (MDA) equivalents per milligram vessel protein.

Vascular superoxide generation. Segments of thoracic aorta $(5 \mathrm{~mm})$ were isolated as described above and maintained in oxygenated PSS at $37^{\circ} \mathrm{C}$. Vessels were incubated with $10 \mathrm{mM}$ diethyldithiocarbamate (DDC, an inhibitor of CuZnSOD [33]) for $30 \mathrm{~min}$ in oxygenated PSS before transfer to scintillation vials containing $2 \mathrm{ml}$ of Hepes-buffered PSS (PSS containing $20 \mathrm{mM}$ Hepes), with $0.25 \mathrm{mM}$ lucigenin (bis- $N$ methylacridium nitrate). After $10 \mathrm{~min}$ of dark adaptation, superoxide generation was estimated as described previously using the chemiluminescence signal from a scintillation counter (model LKB; Wallac Ltd., Gaithersburg, MD) in out of coincidence mode $(18,34,35)$. Chemiluminescence values were obtained at 1 -min intervals over $10 \mathrm{~min}$ and the readings in each of the last 5 min averaged. Background counts were determined from identically processed vessel-free incubations and subtracted from the readings obtained with vessels. Chemiluminescence was inhibited $>95 \%$ by pretreatment of arterial segments with $10 \mathrm{mM}$ Tiron (4,5 dihydroxy-1,3-benzene sulfonic acid salt), a known scavenger of superoxide anions (36).

Vascular superoxide scavenging activity. Vascular superoxide scavenging activity was determined using the method of Salin and McCord (37) with some modification. Segments of thoracic aorta $(\sim 50 \mathrm{mg})$ were harvested as described above and homogenized in PBS ( $2 \mathrm{ml})$ using a homogenizer (Brinkmann Instruments, Inc., Westbury, NY). For the assessment of water-soluble superoxide scavenging activity, the homogenates were centrifuged at $13,600 \mathrm{~g}$ for $15 \mathrm{~min}$ and the supernatant collected and stored on ice until analysis. Water-soluble superoxide scavenging activity was assayed using a xanthine/xanthine oxidase superoxide generating system and the SOD-inhibitable reduction of cytochrome $c$ as follows: The water soluble homogenate $(0.1 \mathrm{ml})$ was incubated with $100 \mu \mathrm{M}$ xanthine, $15 \mu \mathrm{M}$ cytochrome $c$ (horse heart type 
Table I. Plasma Lipid Levels and Animal Weights

\begin{tabular}{lcccc}
\hline & Control & $\begin{array}{c}0.5 \% \\
\text { Cholesterol }\end{array}$ & $\begin{array}{c}1 \% \\
\text { Cholesterol }\end{array}$ & $\begin{array}{c}1 \% \text { Cholesterol } \\
+1 \% \text { probucol }\end{array}$ \\
\hline $\begin{array}{c}\text { Plasma lipids } \\
\text { Total cholesterol } \\
(\mathrm{mg} / \mathrm{dl})\end{array}$ & $70 \pm 25$ & $852 \pm 62^{*}$ & $1,084 \pm 85^{*}$ & $897 \pm 82^{*}$ \\
$\begin{array}{c}\text { Triglycerides } \\
(\mathrm{mg} / \mathrm{dl})\end{array}$ & $122 \pm 43$ & $238 \pm 22^{*}$ & $245 \pm 11^{*}$ & $218 \pm 27^{*}$ \\
$\begin{array}{c}\text { Animal weight } \\
(\mathrm{kg})\end{array}$ & $3.2 \pm 0.4$ & $3.4 \pm 0.3$ & $3.4 \pm 0.4$ & $3.2 \pm 0.5$ \\
\hline
\end{tabular}

All values represent mean \pm SEM of samples from 7 to 12 animals in each group. $* P<0.05$ compared to control group.

IV, Sigma Chemical Co.), $20 \mathrm{mM} \mathrm{NaHCO}_{3}, 1 \mathrm{mM} \mathrm{NaN}_{3}$, and $0.1 \mathrm{mM}$ EDTA $(0.975 \mathrm{ml}$ total vol $)$. The assay was started by the addition of $0.025 \mathrm{ml}$ xanthine oxidase $(1 \mathrm{U} / \mathrm{ml})$ and superoxide generation was estimated by the slope of the absorbance at $550 \mathrm{~nm}$ over the first $30 \mathrm{~s}$ of the reaction. Results were compared to a standard curve obtained using 0.001-1 U/ml bovine erythrocyte CuZnSOD (Sigma Chemical Co.) in place of the homogenate and expressed as units of SOD normalized to the homogenate protein content. The residual non-CuZnSODdependent superoxide scavenging activity was determined from identically prepared vessels that were incubated with $10 \mathrm{mM}$ DDC for $30 \mathrm{~min}$.

For lipid-soluble superoxide scavenging activity, vessel homogenates were extracted with chloroform/methanol (2:1 [ $\mathrm{vol} / \mathrm{vol}])$, dried under nitrogen, and resuspended in $60 \mu \mathrm{l}$ ethanol until analysis. We examined lipid-soluble superoxide scavenging activity in the lipid-soluble homogenate using the method of Misra and Fridovich (38). In this assay, $o$-dianisidine is photooxidized in the presence of riboflavin leading to the formation of a stable product (oxidized dianisidine) that absorbs at $460 \mathrm{~nm}$. Superoxide is also produced in this assay and reduces partially oxidized dianisidine leading to a net decrease in the accumulation of $460-\mathrm{nm}$ product. Thus, compounds that preferentially scavenge superoxide (such as SOD) lead to an increase in $460 \mathrm{~nm}$ absorbance in this assay. In contrast, general free radical scavengers or agents without activity will either decrease $460 \mathrm{~nm}$ absorbance or have no effect, respectively (38). Authentic probucol $(1.9-18.5 \mathrm{nmol} / \mathrm{ml})$ was used as a positive control.

Pathologic examination. The thoracic aorta was perfusion fixed and representative histologic sections of the proximal, mid, and distal thoracic aorta were prepared as described (23). Sections were stained with resorcin fuchsin (for elastin) and subjected to morphometric analysis of intimal and medial area using microscope (model BH-2; Olympus Corp., Lake Success, NY) and an automated videomicroscopy system (Optimas, BioScan Inc., Edmonds, WA).

Tissue cholesterol and lysophosphatidylcholine content. Segments of thoracic aorta not used for superoxide assay were homogenized in the presence of $50 \mu \mathrm{M}$ butylated hydroxytoluene and $0.1 \mathrm{mM}$ diethylenetriaminepentaacetic acid and total lipids extracted with chloroform/ methanol as above. For the determination of cholesterol content, an aliquot $(0.1 \mathrm{ml})$ of lipid extract was dried under nitrogen and resuspended in absolute ethanol. The total cholesterol content (free cholesterol + cholesterol ester) of this lipid suspension was determined using enzymatic methods (26) with a commercially available kit (Sclavo, Inc., Wayne, NJ). The remaining lipid extract was assayed for phosphatidylcholine (PC) and lysophosphatidylcholine (lysoPC) content using the method of Kaduce and colleagues (39).

Data analysis. Unless otherwise specified, all values are presented as a mean $\pm \mathrm{SE}$. The vascular responses to the agents acetylcholine, A23187, and nitroglycerin are reported as the percent relaxation compared to the contraction produced by $1 \mu \mathrm{M}$ norepinephrine. The dose responses to acetylcholine, A23187, and sodium nitroprusside were compared within dietary groups using repeated measures ANOVA. Vas-

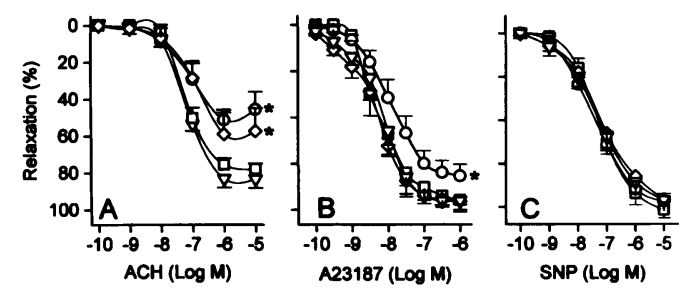

Figure 1. The effects of dietary cholesterol and probucol on vessel relaxation in rabbits. Aortic vessels were harvested from rabbits fed standard chow $(\square), 0.5 \%$ cholesterol chow $(\diamond), 1 \%$ cholesterol chow $(0)$, or $1 \%$ cholesterol chow with $1 \%$ probucol $(\nabla)$ for a period of 28 $\mathrm{d}$ and exposed to the indicated concentrations of $(A)$ acetylcholine $(A C H),(B) \mathrm{A} 23187$, or $(C)$ sodium nitroprusside ( $S N P)$. Vessels were precontracted with $1 \mu \mathrm{M}$ norepinephrine and relaxation reported as the percent reduction in tension from that produced by norepinephrine. Values represent the mean \pm SEM of vessels from six to eight animals in each group; ${ }^{*} P<0.05$ vs control by ANOVA.

cular responses were compared among dietary groups with two-way ANOVA. Comparisons among groups for lipoprotein levels, antioxidant levels, chemiluminescence, superoxide scavenging activity, vascular cholesterol and lysoPC content, and intimal proliferation were performed using ANOVA with a posthoc Neuman-Keuls comparison. Statistical significance was accepted if the null hypothesis was rejected at the $P<0.05$ level.

\section{Results}

Plasma lipid levels and animal weight. Plasma total cholesterol and triglyceride levels, and animal weights in all four dietary treatment groups are contained in Table I. The baseline characteristics of all animals were similar before dietary treatment. Animals fed standard chow demonstrated plasma total cholesterol and triglyceride levels of $70 \pm 25$ and $122 \pm 43 \mathrm{mg} / \mathrm{dl}$, respectively. Animals receiving diets containing 0.5 or $1 \%$ cholesterol for $28 \mathrm{~d}$ demonstrated significant elevations of plasma total cholesterol and triglycerides compared to animals not receiving cholesterol $(P<0.05)$. Similarly, animals receiving a diet supplemented with both $1 \%$ cholesterol and $1 \%$ probucol demonstrated a significant elevation of plasma cholesterol and triglycerides that was not significant different from the other cholesterol-fed groups (Table I). All four treatment groups gained weight to a similar degree over the study period with no significant differences on the basis of dietary treatment (Table I).

Probucol and vascular reactivity. The contractile responses of aortic vessels was similar among the dietary treatment groups. Vessels from animals in the control, $0.5 \%$ cholesterol, $1 \%$ cholesterol, and probucol groups demonstrated contractions to $80 \mathrm{mM} \mathrm{KCl}$ of $5.5 \pm 0.5,5.3 \pm 0.4,6.1 \pm 0.4$, and $5.4 \pm 0.6 \mathrm{~g}$, respectively ( $n=6, P=\mathrm{NS}$ ).

The effects of dietary cholesterol and probucol supplementation on acetylcholine-induced vasodilatation is shown in Fig. 1 $A$. Vessels from rabbits fed standard rabbit chow demonstrated dose-dependent relaxation in response to acetylcholine with a relaxation of $78 \pm 3 \%$ to $10 \mu \mathrm{M}$ acetylcholine $(P<0.001)$. Vessels derived from rabbits in the 0.5 and $1 \%$ cholesterol groups demonstrated significantly impaired responses to acetylcholine with relaxations to $10 \mu \mathrm{M}$ acetylcholine of $57 \pm 11 \%$ and $45 \pm 9 \%$, respectively (both $P<0.05$ vs control). In contrast, rabbits fed a $1 \%$ cholesterol diet supplemented with $1 \%$ probucol demonstrated a response to $10 \mu \mathrm{M}$ acetylcholine 
Table II. LDL Susceptibility to Ex Vivo Copper-mediated Oxidation and LDL Antioxidant Levels

\begin{tabular}{lcccc}
\hline & Control & $\begin{array}{c}0.5 \% \\
\text { Cholesterol }\end{array}$ & $\begin{array}{c}1 \% \\
\text { Cholesterol }\end{array}$ & $\begin{array}{c}1 \% \text { Cholesterol } \\
+1 \% \text { probucol }\end{array}$ \\
\hline $\begin{array}{l}\text { Lag phase (min) } \\
\text { LDL antioxidant } \\
\text { levels (nmol/mg } \\
\quad \text { LDL protein) }\end{array}$ & $96 \pm 7$ & $87 \pm 7$ & $98 \pm 5$ & $224 \pm 12^{*}$ \\
$\begin{array}{c}\alpha \text {-Tocopherol } \\
\text { Probucol }\end{array}$ & $\begin{array}{c}9.3 \pm 0.7 \\
\text { n.d. }\end{array}$ & $\begin{array}{c}10.1 \pm 0.8 \\
\text { n.d. }\end{array}$ & $\begin{array}{c}10.2 \pm 0.7 \\
\text { n.d. }\end{array}$ & $\begin{array}{r}9.8 \pm 0.8 \\
14.5 \pm 3.3\end{array}$ \\
\hline
\end{tabular}

All values represent mean \pm SEM of samples taken from seven to nine animals in each group. ${ }^{*} P<0.001$ compared to control group. n.d., not detected.

$(83 \pm 5 \%)$ that was not significantly different from control rabbits. There was no significant relaxation to acetylcholine in vessels without endothelium (data not shown).

Vessel relaxations to the receptor-independent EDRF agonist, A23187 are presented in Fig. 1 B. Vessels harvested from control rabbits demonstrated significant dose-dependent relaxation in response to A23187 with a maximal response of $95 \pm 6 \%$ $(P<0.001)$. Relaxation in vessels from the $0.5 \%$ cholesterol group was similar to the control group with a maximal relaxation of $95 \pm 5 \%$, whereas vessels derived from the $1 \%$ cholesterol group demonstrated a modest impairment in the response to A23187 compared to control vessels $(81 \pm 5 \%, P<0.05)$. In vessels derived from probucol-treated animals, the response to A23187 was not significantly different than control vessels with a maximal relaxation of $95 \pm 2 \%$ (Fig. $1 B$ ). In vessels without endothelium, there was no significant relaxation to A23187.

The vasodilator response to the NO donor, sodium nitroprusside was similar in the four treatment groups and these results are presented in Fig. $1 C$. Vessels in all four groups demonstrated dose-dependent vasodilatation in response to increasing concentrations of sodium nitroprusside $(P<0.001)$ with no significant differences noted on the basis of dietary treatment or the presence of endothelium.

LDL oxidation studies. Hypercholesterolemia and atherosclerosis are accompanied by the local vascular accumulation of ox-LDL (40) that has been shown to inactivate EDRF directly (15). To determine whether LDL probucol may influence the vascular formation of ox-LDL we assayed plasma-derived LDL in the four treatment groups for resistance to copperinduced oxidation as well as $\alpha$-tocopherol and probucol content (Table II). LDL isolated from rabbits fed chow, $0.5 \%$ cholesterol, or $1 \%$ cholesterol alone demonstrated similar resistance to copper-induced oxidation with lag phase times of $96 \pm 7$, $87 \pm 7$, and $98 \pm 5 \mathrm{~min}$, respectively ( $P=\mathrm{NS}$ ). In contrast, LDL isolated from animals fed $1 \%$ cholesterol and $1 \%$ probucol was markedly resistant to ex vivo copper-induced oxidation as evidenced by a lag phase of $224 \pm 12 \min (P<0.001$ vs control $)$. LDL antioxidant content paralleled the dietary treatment (Table II). LDL derived from all four treatment groups demonstrated similar $\alpha$-tocopherol content. As expected, probucol was detected only in LDL derived from probucol-fed animals at a level of $14.5 \pm 3.3 \mathrm{nmol} / \mathrm{mg}$ LDL protein (Table II).

Vascular accumulation of TBARS. We next sought to determine if the effect of probucol on LDL resistance to oxidative modification was reflected in a reduction of vascular oxidation



Figure 2. The effect of probucol on vascular TBARS content in cholesterol-fed rabbits. Animals were fed diets consisting of standard chow ( $C T L)$, chow with $0.5 \%$ cholesterol $(0.5 \% \mathrm{CHOL})$, chow with $1 \%$ cholesterol ( $1 \% \mathrm{CHOL}$ ), or chow with $1 \%$ cholesterol and $1 \%$ probucol $(P B)$. After $28 \mathrm{~d}$, segments of thoracic aorta were harvested and assayed for TBARS as described in Methods. Values represent the mean \pm SEM of vessels derived from seven to nine animals; $* P<0.05$ vs control by ANOVA.

products. Therefore, we determined the level of TBARS in segments of thoracic aorta from animals used in this study and these results are presented in Fig. 2. In control animals, the level of thoracic TBARS was $0.58 \pm 0.13 \mathrm{nmol} \mathrm{MDA} / \mathrm{mg}$ protein, whereas vessel segments from animals in the 0.5 and $1 \%$ cholesterol groups exhibited elevated values of $1.75 \pm 0.39 \mathrm{nmol}$ $\mathrm{MDA} / \mathrm{mg}$ protein and $1.70 \pm 0.37 \mathrm{nmol} \mathrm{MDA} / \mathrm{mg}$ protein, respectively ( $P<0.05$ vs control $)$. In contrast, vessel segments from animals fed $1 \%$ cholesterol and $1 \%$ probucol demonstrated TBARS of $0.71 \pm 0.12 \mathrm{nmol} \mathrm{MDA} / \mathrm{mg}$ protein and this was not significantly different from control animals.

Endothelium-dependent arterial relaxation and indices of antioxidant protection. To investigate whether vascular oxidative stress is associated with impaired vascular reactivity, we examined the relationship between the antioxidant effects of probucol and endothelium-dependent arterial relaxation. We found a strong association between indices of antioxidant protection and preservation of endothelial function (Fig. 3). LDL resistance to ex vivo copper-induced oxidation correlated with receptor-mediated endothelium-dependent arterial relaxation to acetylcholine $(r=0.59, P=0.0007$; Fig. $3 A$ ). In addition, arterial relaxation to acetylcholine also correlated with vascular TBARS $(r=-.54, P=0.008$; Fig. $3 B$ ), an indirect indicator of vascular oxidative stress. In contrast, we did not see any significant association between relaxation to A23187 and LDL lag phase $(r=0.07 ; P=0.77)$ or vascular TBARS $(r=0.17$; $P=0.41)$.

Estimation of vascular superoxide generation. The precise source $(s)$ of vascular oxidative stress and the mechanism(s) of ox-LDL formation in vivo are unknown. However, several investigators have implicated cellular superoxide generation as a critical event for both cellular LDL modification (41-43) and inactivation of EDRF $(16,17)$. We sought to determine if the beneficial effects of probucol on vascular oxidative stress and EDRF action may be a consequence of reduced vascular superoxide generation. Vascular superoxide generation from the thoracic aorta of all four treatment groups was estimated using lucigenin chemiluminescence $(18,34,35)$ in the presence of 

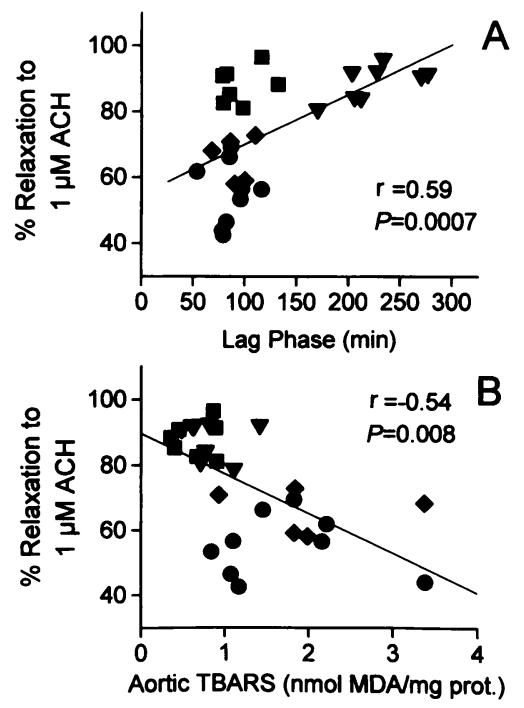

Figure 3. Plots demonstrating the relationship between receptor-mediated endothelium-dependent arterial relaxation and: (A) LDL resistance to oxidative modification; $(B)$ vascular TBARS. Animals were fed diets consisting of standard chow: (घ), $0.5 \%$ cholesterol chow $(\bullet), 1 \%$ cholesterol chow $(\bullet)$, or $1 \%$ cholesterol chow with $1 \%$ probucol ( $\mathbf{v})$. After $28 \mathrm{~d}$, segments of thoracic aorta were harvested and assayed for endotheliumdependent relaxation and TBARS content. LDL

was isolated from fresh plasma obtained at the time of death and assayed for resistance to ex vivo copper-induced oxidation. Data were taken from all 29 animals for which simultaneous observations were available.

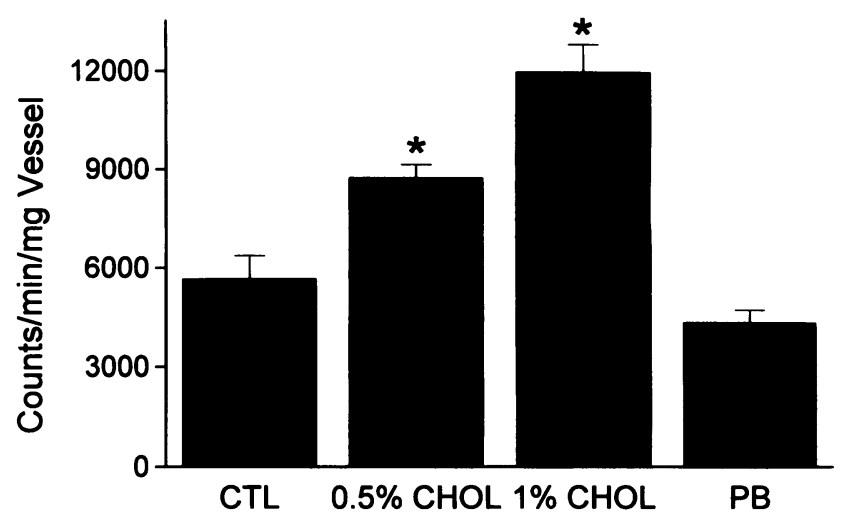

Figure 4. The effect of dietary probucol on vascular superoxide generation in cholesterol-fed rabbits. Segments of thoracic aorta $(5 \mathrm{~mm})$ were harvested from animals fed diets consisting of standard chow (CTL), chow with $0.5 \%$ cholesterol $(0.5 \% C H O L)$, chow with $1 \%$ cholesterol $(1 \% \mathrm{CHOL}$ ), or chow with $1 \%$ cholesterol and $1 \%$ probucol $(P B)$. Vessels were incubated with DDC for 30 min and chemiluminescence assayed with $0.25 \mathrm{mM}$ lucigenin as described in Methods. Values represent the mean \pm SEM of vessels harvested from six animals in each group. ${ }^{*} P<0.05$ vs CTL by ANOVA.

(Table III). The tissue content of lipid-soluble antioxidants is also contained in Table III and demonstrates that the arterial content of $\alpha$-tocopherol was not significantly different among dietary groups. As expected, probucol was detected only in the aorta of animals consuming $1 \%$ cholesterol and $1 \%$ probucol (Table III). Thus, the addition of probucol to a cholesterol diet reduced vascular superoxide generation, but did not increase vascular superoxide scavenging activity.

Pathologic examination of vascular tissue and vascular tissue composition. Previous studies have linked endothelial dysfunction to the extent of atherosclerosis in animal models (48, 49 ) and probucol inhibits atherogenesis in some experimental models $(50,51)$. The effects of dietary intervention on atherogenesis was assessed by evaluating the extent of intimal proliferation in segments of thoracic aorta (Table IV). Using the ratio of intimal area to medial area as an index of intimal proliferation, aortas derived from the 0.5 and $1 \%$ cholesterol groups demonstrated intimal to medial ratios of $4.36 \pm 1.80 \times 10^{-3}$ and $9.74 \pm 2.40 \times 10^{-3}$, respectively $(P<0.05$ vs control for $1 \%$ cholesterol group only). The intimal to medial ratio in the probucol group $8.26 \pm 1.74 \times 10^{-3}$ was not significantly different from the other cholesterol-fed groups $(P=0.23)$. In contrast, vessels derived from control animals exhibited no significant intimal proliferation with an intimal to medial ratio of $0.56 \pm 0.45 \times 10^{-3}$.

As shown in Fig. 4 and reported previously (18), hypercholesterolemia in rabbits is associated with excess net vascular superoxide production, and dietary treatment of hypercholesterolemia corrects this abnormality (52). Probucol is known to limit atherogenesis and the vascular accumulation of cholesterol in animal models (53). Therefore, we examined whether the decreased rate of superoxide generation in probucol-fed animals could be explained by decreased vascular cholesterol content. As shown in Table IV, thoracic aortas derived from animals consuming normal rabbit chow had the lowest tissue cholesterol content of $0.48 \pm 0.18 \mathrm{mg} / \mathrm{g}$. Vessels derived from animals consuming 0.5 and $1 \%$ cholesterol chow had cholesterol contents 


\begin{tabular}{|c|c|c|c|c|}
\hline & Control & $0.5 \%$ Cholesterol & $1 \%$ Cholesterol & $\begin{array}{l}1 \% \text { Cholesterol } \\
+1 \% \text { probucol }\end{array}$ \\
\hline \multicolumn{5}{|l|}{ Superoxide scavenging activity } \\
\hline CuZnSOD (IU/mg protein) & $5.09 \pm 1.49$ & $5.18 \pm 1.15$ & $5.68 \pm 0.86$ & $6.04 \pm 1.39$ \\
\hline Residual water-soluble (IU SOD/mg protein) & $0.97 \pm 0.33$ & $0.96 \pm 0.40$ & $0.89 \pm 0.51$ & $1.28 \pm 0.52$ \\
\hline Lipid-soluble $\left(\Delta \mathrm{OD}_{460 \mathrm{~nm}}\right)$ & $0.085 \pm 0.03$ & $0.066 \pm 0.015$ & $0.067 \pm 0.017$ & $0.057 \pm 0.019$ \\
\hline \multicolumn{5}{|l|}{ Aortic antioxidant content } \\
\hline$\alpha$-Tocopherol (nmol/g) & $3.9 \pm 0.8$ & $4.4 \pm 1.1$ & $5.8 \pm 1.2$ & $2.8 \pm 0.8$ \\
\hline Probucol (nmol/g) & $<0.001$ & $<0.001$ & $<0.001$ & $0.43 \pm 0.17^{*}$ \\
\hline
\end{tabular}

Aortic vessels were harvested from rabbits fed standard chow, $0.5 \%$ cholesterol chow, $1 \%$ cholesterol chow, or $1 \%$ cholesterol chow with $1 \%$ probucol for a period of $28 \mathrm{~d}$ and vascular antioxidant content, CuZnSOD activity, and residual water-soluble superoxide scavenging activity determined as described in Methods. Lipid-soluble superoxide scavenging activity is expressed as $\Delta \mathrm{OD}_{460 \mathrm{~mm}}$ per $10 \mathrm{mg}$ tissue over a 4 -min assay with a greater $\Delta O D_{460 \mathrm{~nm}}$ associated with more superoxide scavenging activity. For comparison, probucol at concentrations of 1.9, 4.6, 9.3, and 18.5 $\mathrm{nmol} / \mathrm{ml}$ produced a $\Delta \mathrm{OD}_{460 \mathrm{~mm}}$ of $0.044 \pm 0.007,0.055 \pm 0.005,0.075 \pm 0.005$, and $0.107 \pm 0.002$, respectively. Data are presented as mean $\pm \mathrm{SEM}$ and represent values derived from four to eight animals in each group. $* P<0.05$ vs control.

of $1.23 \pm 0.26 \mathrm{mg} / \mathrm{g}$ and $1.51 \pm 0.42 \mathrm{mg} / \mathrm{g}$, respectively (both $P$ $<0.05$ vs chow-fed animals). The cholesterol content of thoracic aortas from animals consuming $1 \%$ cholesterol and $1 \%$ probucol was $1.26 \pm 0.35 \mathrm{mg} / \mathrm{g}$, and this was not significantly different from the other cholesterol-fed animals. Thus, in this model, the addition of probucol to a $1 \%$ cholesterol diet did not significantly reduce the cholesterol content of thoracic aorta.

Recent evidence indicates that normal arteries exposed to lysoPC demonstrate excess net vascular superoxide production via a protein kinase $\mathrm{C}$-mediated mechanism (34). LDL oxidation is associated with intraparticle conversion of $\mathrm{PC}$ to lysoPC (54), and probucol has been shown to limit LDL oxidation (21) and the vascular accumulation of ox-LDL in experimental atherosclerosis (51). In thoracic aortas derived from animals consuming 0.5 and $1 \%$ cholesterol the lysoPC content was significantly elevated compared to chow-fed animals (both $P$ $<0.05$ vs chow-fed animals ). In animals consuming $1 \%$ cholesterol with $1 \%$ probucol, the lysoPC content of thoracic aorta was not significantly different from chow-fed animals (Table IV). With respect to the aortic content of PC, this parameter was reduced only in the animals fed $1 \%$ cholesterol alone (Table IV). We also found a significant reduction in the ratio of PC to lysoPC, an index of phospholipid oxidation, in animals fed 0.5 or $1 \%$ cholesterol alone. In contrast, animals fed $1 \%$ choles- terol with $1 \%$ probucol did not demonstrate a significant reduction in the ratio of PC to lysoPC (Table IV). Thus, the addition of probucol to a $1 \%$ cholesterol diet was associated with a significant reduction in vascular phospholipid oxidation and the vascular content of lysoPC.

To substantiate a role for lysoPC in vascular superoxide generation, we examined the relationship between the vascular chemiluminescence signal in the presence of DDC and phospholipid oxidation (Fig. 5). We found that vascular superoxide generation positively correlated with the vascular content of lysoPC ( $r=0.75, P=0.001$; Fig. $5 A$ ), and inversely correlated with the ratio of $\mathrm{PC}$ to lysoPC in the thoracic aorta $(r=-0.67$; $P=0.006$; Fig. $5 \mathrm{~B}$ ). In contrast, there was no significant correlation between vascular cholesterol content and superoxide generation $(r=0.25 ; P=0.36)$.

\section{Discussion}

The data presented here demonstrate that probucol, a lipidsoluble antioxidant, prevents the development of endothelial vasodilator dysfunction in cholesterol-fed rabbits. The prevention of endothelial dysfunction was not a consequence of probucol-mediated effects on plasma cholesterol, intimal proliferation, or any alteration in smooth muscle sensitivity to sodium

Table IV. Intimal Proliferation and Aortic Cholesterol and Phospholipid Content

\begin{tabular}{lcccc}
\hline & Control & $0.5 \%$ Cholesterol & 1\% Cholesterol $\begin{array}{r}1 \% \text { Cholesterol } \\
+1 \% \text { probucol }\end{array}$ \\
\hline Aortic intimal-to-medial ratio $\left(\times 10^{-3}\right)$ & $0.56 \pm 0.45$ & $4.36 \pm 1.80$ & $9.74 \pm 2.40^{*}$ & $8.26 \pm 1.74 *$ \\
Aortic cholesterol $(\mathrm{mg} / \mathrm{g})$ & $0.48 \pm 0.18$ & $1.23 \pm 0.2^{*}$ & $1.51 \pm 0.42^{*}$ & $1.26 \pm 0.35^{*}$ \\
Aortic lysophosphatidylcholine $(\mu \mathrm{mol} / \mathrm{g})$ & $0.43 \pm 0.13$ & $1.05 \pm 0.32^{*}$ & $0.89 \pm 0.09 *$ & $0.49 \pm 0.08$ \\
Aortic phosphatidylcholine $(\mu \mathrm{mol} / \mathrm{g})$ & $7.06 \pm 2.38$ & $8.22 \pm 1.49$ & $4.65 \pm 0.88^{*}$ & $5.72 \pm 1.15$ \\
Ratio PC to lysoPC & $19.64 \pm 5.21$ & $9.22 \pm 1.18^{*}$ & $5.07 \pm 0.86^{*}$ & $12.33 \pm 2.78$ \\
& & & & \\
\hline
\end{tabular}

Aortic segments were harvested from rabbits fed standard chow, $0.5 \%$ cholesterol chow, $1 \%$ cholesterol chow, or $1 \%$ cholesterol chow with $1 \%$ probucol for a period of $28 \mathrm{~d}$. The vessels were fixed and prepared as described in Methods, embedded in paraffin, and stained for elastin. Sections of proximal descending aorta were subjected to morphometric analysis of intimal area and medial area using an automated videomicroscopy system. Values are displayed as mean \pm SEM and represent analysis of six sections per animal taken from six animals in each group. Aortic cholesterol and phospholipid levels were determined as described in Methods and represent data taken from 6-10 animals in each group. ${ }^{*} P<0.05$ vs control. 


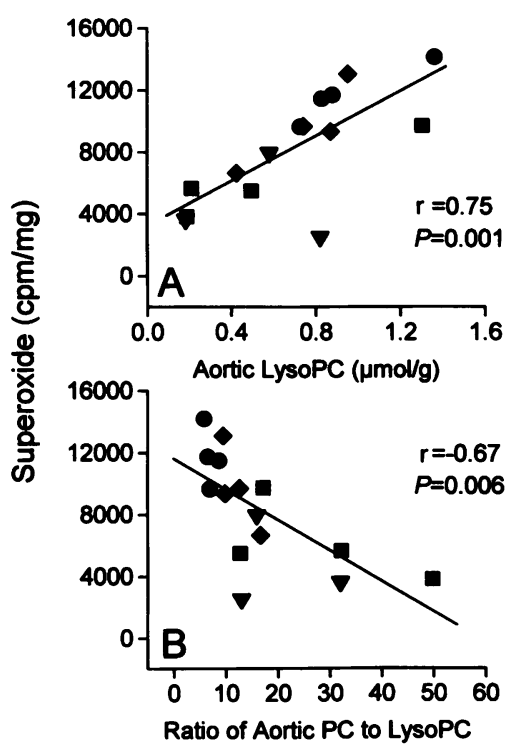

nitroprusside. Compared to cholesterol feeding alone, probucol treatment resulted in the protection of LDL against ex vivo copper-induced oxidation and this antioxidant effect was significantly correlated to receptor-mediated EDRF action. Likewise, probucol treatment prevented the increase in vascular oxidative stress that was associated with cholesterol feeding. Compared to animals fed cholesterol alone, probucol-treated animals demonstrated reductions in both vascular superoxide generation and the vascular content of TBARS. In particular, the effect of probucol on vascular superoxide generation was closely associated with indices of tissue phospholipid oxidation such as the vascular lysoPC content and the ratio of PC to lysoPC in the vessel wall.

The preservation of EDRF action in cholesterol-fed rabbits by probucol has been reported previously by Simon and colleagues (22). These investigators found that dietary probucol preserved endothelium-dependent arterial relaxation in rabbits fed a $0.5 \%$ (wt/wt) cholesterol diet for $10 \mathrm{wk}$. In addition, Simon and coworkers found that probucol had no effect on endothelium-dependent arterial relaxation in normal rabbits, ruling out the possibility that probucol treatment results in a nonspecific enhancement of EDRF action. These authors also suggested that the effect of probucol was related to its antioxidant activity as manifested by a reduction in the plasma content of TBARS. In contrast to the present study, Simon and colleagues did not find any change in tissue TBARS associated with cholesterol feeding. Potential reasons for this discrepancy include differences in the methods used for TBARS measurement and differences in the dietary regimen. We used a batch method for TBARS assessment while Simon and colleagues used an HPLC method with fluorometric detection. In addition, our animals consumed only cholesterol while Simon and coworkers used a diet containing peanut oil. Moreover, these investigators did not examine LDL resistance to oxidation or tissue generation of reactive oxygen species and thus, did not assess the antioxidant activity of probucol directly. Nevertheless, the findings of Simon and colleagues are in general agreement with the findings presented here, indicating that the antioxidant properties of probucol are central to the preservation of EDRF action in hypercholesterolemia.
Probucol is extremely effective in preventing both copperand cell-mediated LDL oxidation (21). Normal rabbit arteries exposed to ox-LDL develop impaired endothelium-dependent arterial relaxation (12) and ox-LDL has been shown to inactivate EDRF directly (15). Thus, one possible mechanism for the beneficial effect of probucol on endothelial function in this study is the reduced formation of ox-LDL in the vascular wall. This contention is supported by our observations that LDL derived from probucol-treated animals demonstrated enhanced resistance to ex vivo copper-induced oxidation and this effect correlated with receptor-mediated EDRF action. Moreover, probucol treatment of cholesterol-fed animals was associated with a significant reduction in the TBARS content of thoracic aorta that also correlated with preserved EDRF action. Since LDL oxidation is associated with the formation of TBARS within the particle (55) and clinically relevant LDL oxidation occurs in the vessel wall (56), these data are consistent with reduced ox-LDL formation in vivo. It is important to interpret these findings with some caution, however, as the measurement of TBARS in biologic samples is not specific for the formation of ox-LDL (57).

The oxidation of LDL involves lipid peroxidation and the conversion of PC to lysoPC within the LDL particle (54). We found increased levels of lysoPC in the thoracic aorta of cholesterol-fed animals, whereas animals fed both cholesterol and probucol had normal arterial lysoPC content (Table IV). Similarly, the ratio of PC to lysoPC, an index of phospholipid oxidation, was significantly reduced in cholesterol-fed animals compared to animals that consumed both probucol and cholesterol. Taken together, these findings also support the hypothesis that probucol prevents the formation of ox-LDL in the arterial wall of cholesterol-fed rabbits.

The accumulation of lysoPC in the arterial wall has potential implications for endothelium-dependent arterial relaxation. The transfer of lysoPC from ox-LDL to endothelial cells has been demonstrated in vitro (12) and results in abnormal receptormediated EDRF action through the inhibition of membraneassociated inhibitory $G$ proteins (58). Our findings are consistent with these effects of lysoPC on EDRF action. We found that animals fed 0.5 or $1 \%$ cholesterol developed abnormal endothelium-dependent arterial relaxation to acetylcholine, $a G_{i}$ protein-dependent EDRF agonist, in association with the arterial accumulation of lysoPC and a reduction in the ratio of arterial PC to lysoPC. Relaxation responses to A23187, a receptor-independent EDRF agonist, were less sensitive to these changes and this is consistent with previous reports (for review see reference 58). In contrast, probucol-treated animals had normal levels of lysoPC in the thoracic aorta and normal responses to both acetylcholine and A23187. Thus, our data indicate that in cholesterol-fed rabbits, probucol protects LDL against oxidation in vivo with a concomitant reduction in vascular oxidative stress and, as a consequence, prevents the accumulation of lysoPC in arterial tissue.

Recent studies have demonstrated that lysoPC stimulates net smooth muscle cell production of superoxide in rabbit aorta through a protein kinase $\mathrm{C}$-mediated mechanism (34). In this study, we found that animals consuming cholesterol demonstrated a dose-dependent increase in vascular superoxide generation, whereas probucol-treated animals did not demonstrate such changes (Fig. 4). More importantly, we found that both the aortic content of lysoPC and the ratio of PC to lysoPC correlated strongly with vascular superoxide generation (Fig. 
5). One possible interpretation of these data is that probucol prevented increased vascular superoxide generation in cholesterol-fed rabbits through a reduction in the tissue content of lysoPC. Consistent with this interpretation, we found enhanced antioxidant protection of LDL in probucol-treated animals (Table II). We would submit that incorporation of probucol into LDL limits LDL oxidation in the vascular wall and, as a consequence, limits the local formation of lysoPC resulting in a diminished stimulus for protein kinase $\mathrm{C}$-mediated superoxide generation (34).

The prevention of LDL oxidation by probucol is generally attributed to its incorporation into the LDL particle (59). We report here an effect of probucol on vascular superoxide generation that provides an additional mechanism for reduced LDL oxidation with probucol treatment. Current evidence suggests that cell-mediated LDL oxidation is facilitated by superoxide $(41-43)$, possibly via the reduction of redox-active iron (60) that is available in the vascular wall (61). Therefore, any reduction in superoxide formation resulting from probucol treatment would also limit the formation of ferrous iron in the vascular wall and thus, limit the oxidation of LDL.

We observed an increase in vascular superoxide generation from the thoracic aorta of cholesterol-fed rabbits that was associated with impaired endothelium-dependent arterial relaxation (Fig. $1 A$ and Fig. 4). Since EDRF is readily inactivated by superoxide $(16)$, it is attractive to speculate that probucol treatment preserved EDRF action, in part, by limiting vascular superoxide generation and thus, preventing direct inactivation of EDRF. There is considerable evidence indicating that reducing the availability of superoxide in hypercholesterolemia and atherosclerosis is beneficial for EDRF action. Cholesterol-fed rabbits chronically treated with polyethylene glycol-conjugated SOD demonstrate enhanced tissue SOD activity and improved endothelium-dependent arterial relaxation (19). Likewise, dysfunctional arteries derived from atherosclerotic rabbits demonstrate improved endothelium-dependent relaxation and increased intracellular SOD activity after treatment with liposome-encapsulated SOD (20).

The availability of superoxide in vascular tissues is related to the relative rates of superoxide generation and inactivation. Our data would indicate that dietary probucol truly limits the generation of superoxide from cholesterol-fed rabbit thoracic aorta. We found no difference in CuZnSOD activity, or residual water- and lipid-soluble superoxide scavenging activity of thoracic aorta on the basis of dietary treatment. Furthermore, we specifically assessed vascular superoxide generation in the presence of DDC, an inhibitor of CuZnSOD (33), to estimate the total generation of superoxide. The particular importance of total vascular superoxide generation is readily apparent from kinetic data on the interaction of superoxide with NO. Superoxide and NO react with a diffusion-limited rate constant of $\sim 6.7$ $\times 10^{9} \mathrm{M}^{-1} / \mathrm{s}^{-1}(62)$ that is fourfold greater than the rate constant for SOD-mediated superoxide dismutation (63) $(\sim 1.6$ $\left.\times 10^{9} \mathrm{M}^{-1} / \mathrm{s}^{-1}\right)$. Thus, available kinetic data indicate that NO effectively competes with SOD for superoxide and as a consequence, all superoxide generated within the cell is potentially available for interaction with NO.

We found a dose-dependent effect of cholesterol feeding on vascular superoxide generation suggesting that cholesterol itself may stimulate the generation of superoxide from vascular segments. Since plasma cholesterol did not vary significantly as a function of dietary group, it seems unlikely that the plasma

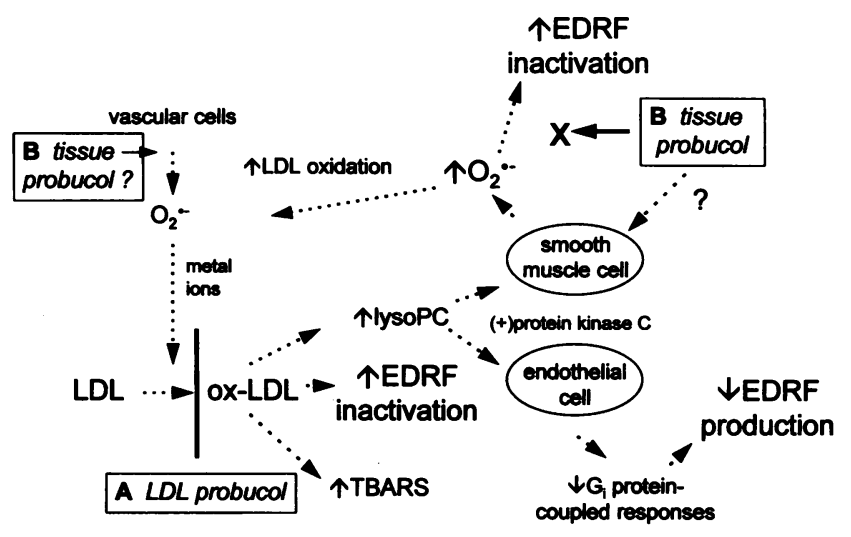

Figure 6. Proposed scheme for the effect of probucol on EDRF action and metabolism in cholesterol-fed rabbits. LDL is incorporated into the arterial wall where it is subject to cell-mediated oxidation. The oxidation of LDL is associated with the conversion of PC to lysoPC resulting in the activation of protein kinase $C$ in endothelial and smooth muscle cells resulting in: $(a)$ inhibition of receptor-mediated EDRF action and (b) enhanced net superoxide production. Superoxide is then available for direct inactivation of EDRF as well as promotion of LDL oxidation through the reduction of ferric iron. Potential sites for probucol action include: $(A)$ the inhibition of LDL oxidation via probucol incorporation into LDL and, perhaps $(B)$ prevention of superoxide production via a direct cellular effect. There is no evidence for direct superoxide scavenging by probucol.

cholesterol levels alone would explain the results reported here. Similarly, tissue cholesterol levels do not completely explain the effect of probucol on superoxide generation because probucol treatment did not reduce tissue cholesterol to control values (Table IV), while it did reduce vascular superoxide generation to control levels. Probucol also did not significantly reduce intimal proliferation suggesting that this parameter was not responsible for the observed effect of probucol on vascular superoxide generation.

There is one report indicating that probucol scavenges superoxide anion in vitro (47). One must consider, therefore, that the effect of probucol on vascular superoxide generation is a consequence of direct superoxide scavenging in vascular tissue. We consider this possibility unlikely for two reasons. First, we were unable to detect any superoxide scavenging activity with probucol using xanthine/xanthine oxidase and superoxide detection with lucigenin chemiluminescence, or cytochrome $c$ reduction (data not shown). Second, using the most favorable assay for detecting superoxide scavenging activity with probucol (i.e., photooxidation of dianisidine), we were also unable to detect a significant increase in lipid-soluble superoxide scavenging activity in probucol-treated animals (Table III).

We would propose the following scheme for the effects of probucol observed in this study (Fig. 6). In cholesterol-fed animals, LDL accumulates in the subendothelial space of the vascular wall and is subject to oxidation by resident vascular cells (9-11) leading to direct inactivation of EDRF (15), the conversion of PC to lysoPC (54), and TBARS formation (54). The local accumulation of lysoPC produces smooth muscle cell (34) and endothelial cell (64) protein kinase C activation, resulting in the increased availability of superoxide in smooth muscle cells (34) and a reduction in receptor-mediated EDRF release from endothelial cells (64). The increased availability of superoxide has the dual effect of inactivating superoxide 
directly and enhancing LDL oxidation through the reduction of iron (60) that is available in the vascular wall (61). Our data support a role for the inhibition of LDL oxidation by LDL probucol (Fig. 6, $A$ ) preventing the cascade of events outlined above. Additionally, a direct effect of probucol on vascular superoxide generation (Fig. 6, B) cannot be excluded as this would also explain the reduction in tissue TBARS and lysoPC content reported here. Presently, we have no direct evidence for such an effect although direct effects of probucol on vascular cells have been described $(65,66)$. There is no evidence for direct scavenging of superoxide by probucol in vascular tissue.

In summary, the data presented here indicate that antioxidant treatment with probucol effectively improves EDRF action in cholesterol-fed rabbits. Moreover, the preservation of EDRF action is directly related to the antioxidant activity of probucol as manifested by a reduction in the vascular content of TBARS and lysoPC, as well as a reduction in the vascular generation of superoxide. These data provide evidence that the disturbances of vasomotor function associated with hypercholesterolemia result, in part, from an imbalance between vascular oxidative stress and antioxidant protection. In addition, these data are consistent with the hypothesis that antioxidants may benefit patients with hypercholesterolemia and atherosclerosis by reducing vascular oxidative stress and thus, improving EDRF action.

\section{Acknowledgments}

This work was supported by grants from the American Heart Association (J. A. Vita, B. Frei, and J. F. Keaney, Jr.) and the National Institutes of Health (HI-49954 to B. Frei). John F. Keaney, Jr., is the recipient of a National Research Service Award (F32HL08635) from the National Institutes of Health and a Pfizer Postdoctoral Fellowship. Joseph A. Vita is the recipient of a Clinical Investigator Award (K08HL02580) from the National Institutes of Health.

\section{References}

1. Vanhoutte, P. M. 1993. Other endothelium-derived vasoactive factors. Circulation. 87:V9-V17.

2. Ignarro, L. J., G. M. Buga, K. S. Wood, R. E. Byrns, and G. Chaudhuri. 1987. Endothelium-derived relaxing factor produced and released from artery and vein is nitric oxide. Proc. Natl. Acad. Sci. USA. 84:9265-9269.

3. Stamler, J. S., D. J. Singel, and J. Loscalzo. 1992. Biochemistry of nitric oxide and its redox-activated forms. Science (Wash. DC). 258:1898-1902.

4. Ignarro, L. J., T. M. Burke, K. S. Wood, M. S. Wolin, and P. J. Kadowitz. 1984. Association between cyclic GMP accumulation and acetylcholine-elicited relaxation of bovine intrapulmonary artery. J. Pharmacol. Exp. Ther. 228:682690.

5. Azuma, H., M. Ishikawa, and S. Sekizaki. 1986. Endothelium-dependent inhibition of platelet aggregation. Br. J. Pharmacol. 88:411-415.

6. Vita, J. A., C. B. Treasure, E. G. Nabel, J. M. McLenachan, R. D. Fish, A. C. Yeung, V. I. Vekshtein, A. P. Selwyn, and P. Ganz. 1990. Coronary vasomotor response to acetylcholine relates to risk factors for coronary artery disease. Circulation. 81:491-497.

7. Ludmer, P. L., A. P. Selwyn, T. L. Shook, R. R. Wayne, G. H. Mudge, R. W. Alexander, and P. Ganz. 1986. Paradoxical vasoconstriction induced by acetylcholine in atherosclerotic coronary arteries. N. Engl. J. Med. 315:10461051 .

8. Sorenson, K. E., D. S. Celermajer, D. Georgakopoulos, G. Hatcher, D. J. Betteridge, and J. E. Deanfield. 1994. Impairment of endothelium-dependent dilation is an early event in children with familial hypercholesterolemia and is related to the lipoprotein (a) level. J. Clin. Invest. 93:50-55.

9. Henriksen, T., E. M. Mahoney, and D. Steinberg. 1981. Enhanced macrophage degradation of low density lipoprotein previously incubated with cultured endothelial cells: recognition by receptor for acetylated low density lipoproteins. Proc. Natl. Acad. Sci. USA. 78:6499-6503.

10. Heinecke, J. W., H. Rosen, and A. Chait. 1984. Iron and copper promote modification of low density lipoprotein by arterial smooth muscle cells. J. Clin. Invest. 74:1890-1894.

11. Parthasarathy, S., D. J. Printz, D. Boyd, L. Joy, and D. Steinberg. 1986. Macrophage oxidation of low density lipoprotein generates a modified form recognized by the scavenger receptor. Arteriosclerosis. 6:505-510.

12. Kugiyama, K., S. A. Kerns, J. D. Morrisett, R. Roberts, and P. D. Henry. 1990. Impairment of endothelium-dependent arterial relaxation by lysolecithin in modified low-density lipoproteins. Nature (Lond.). 344:160-162.

13. Inoue, N., K. Hirata, M. Yamada, Y. Hamamori, Y. Matsuda, H. Akita, and M. Yokoyama. 1992. Lysophosphatidylcholine inhibits bradykinin-induced phosphoinositide hydrolysis and calcium transients in cultured bovine aortic endothelial cells. Circ. Res. 71:1410-1421.

14. Morel, D. W., G. M. Hessler, and G. M. Chisolm. 1983. Low density lipoprotein cytotoxicity induced by free radical peroxidation of lipid. J. Lipid Res. 24:1070-1076.

15. Chin, J. H., S. Azhar, and B. B. Hoffman. 1992. Inactivation of endothelium-derived relaxing factor by oxidized lipoproteins. J. Clin. Invest. 89:10-18.

16. Rubanyi, G. M., and P. M. Vanhoutte. 1986. Superoxide anions and hyperoxia inactivate endothelium-derived relaxing factor. Am. J. Physiol. 250:H822-H827.

17. Mugge, A., J. K. Elwell, T. E. Peterson, and D. G. Harrison. 1991. Release of intact endothelium-derived relaxing factor depends on endothelial superoxide dismutase activity. Am. J. Physiol. 260:C219-C225.

18. Ohara, Y., T. E. Peterson, and D. G. Harrison. 1993. Hypercholesterolemia increases endothelial superoxide anion production. J. Clin. Invest. 91:2546-2551.

19. Mugge, A., J. H. Elwell, T. E. Peterson, T. G. Hofmeyer, D. D. Heistad, and D. G. Harrison. 1991. Chronic treatment with polyethylene-glycolated superoxide dismutase partially restores endothelium-dependent vascular relaxations in cholesterol-fed rabbits. Circ. Res. 69:1293-1300.

20. White, C. R., T. A. Brock, L.-Y. Chang, J. Crapo, P. Briscoe, D. Ku, W. A. Bradley, S. H. Gianturco, J. Gore, B. A. Freeman, and M. M. Tarpey. 1994. Superoxide and peroxynitrite in atherosclerosis. Proc. Natl. Acad. Sci. U.SA. 91:1044-1048

21. Parthasarathy, S., S. G. Young, J. L. Witztum, R. C. Pittman, and D. Steinberg. 1986. Probucol inhibits oxidative modification of low density lipoprotein. J. Clin. Invest. 77:641-644.

22. Simon, B. C., C. C. Haudenschild, and R. A. Cohen. 1993. Preservation of endothelium-dependent relaxation in atherosclerotic rabbit aorta by probucol J. Cardiovasc. Pharmacol. 21:893-901.

23. Keaney, J. F., Jr., J. M. Gaziano, A. Xu, B. Frei, J. Curran-Celantano, G. T. Shwaery, J. Loscalzo, and J. A. Vita. 1993. Dietary antioxidants preserve endothelium-dependent vessel relaxation in cholesterol-fed rabbits. Proc. Natl. Acad. Sci. USA. 90:11880-11884.

24. Andersson, T. L. G., J. Matz, G. A. A. Ferns, and E. A. Änggård. 1994. Vitamin $E$ reverses cholesterol-induced endothelial dysfunction in the rabbit coronary circulation. Atherosclerosis. 111:39-45.

25. Raij, L., J. Jagy, K. Coffee, and E. G. DeMaster. 1993. Hypercholesterolemia promotes endothelial dysfunction in vitamin E- and selenium-deficient rats. Hypertension (Dallas). 22:56-61.

26. Allain, C. C., L. S. Poon, C. S. Chen, W. Richmond, and P. C. Fu. 1974. Enzymatic determination of total serum cholesterol. Clin. Chem. 20:470-475.

27. Bucolo, G., and H. David. 1973. Quantitative determinations of serum triglycerides by the use of enzymes. Clin. Chem. 19:476-482.

28. Mao, S. J. T., M. T. Yates, R. A. Parker, E. M. Chi, and R. L. Jackson. 1991. Attenuation of atherosclerosis in a modified strain of hypercholesterolemic Watanabe rabbits with the use of a probucol analogue (MDL 29,311) that does not lower serum cholesterol. Arterioscler. Thromb. 11:1266-1275.

29. Stocker, R., V. W. Bowry, and B. Frei. 1991. Ubiquinol-10 protects human low density lipoprotein more efficiently against lipid peroxidation than does alphatocopherol. Proc. Natl. Acad. Sci. USA. 88:1646-1650.

30. Keaney, J. F., Jr., J. M. Gaziano, A. Xu, B. Frei, J. Curran-Celentano, G. T. Shwaery, J. Loscalzo, and J. A. Vita. 1994. Low-dose $\alpha$-tocopherol improves and high-dose $\alpha$-tocopherol worsens endothelial vasodilator function in cholesterol-fed rabbits. J. Clin. Invest. 93:844-851.

31. Esterbauer, H., G. Striegl, H. Puhl, S. Oberreither, M. Rotheneder, M. ElSaadani, and J. Jürgens. 1989. The role of vitamin $E$ and carotenoids in preventing oxidation of low density lipoprotein. Ann. NY Acad. Sci. 570:254-267.

32. Lowry, O. H., N. J. Rosebrough, A. L. Farr, and R. J. Randall. 1951. Protein measured with the folin phenol reagent. J. Biol. Chem. 193:265-275.

33. Heikkila, R. E., and G. Cohen. 1977. The inactivation of copper-zinc superoxide dismutase by diethyldithiocarbamate. In Superoxide and Superoxide Dismutases. Academic Press Limited, London. 367-373.

34. Ohara, Y., T. E. Peterson, B. Zheng, J. F. Kuo, and D. G. Harrison. 1994. Lysophosphatidylcholine increases vascular superoxide anion production via protein kinase C activation. Arterioscler. Thromb. 14:1007-1013.

35. Omar, H. A., P. D. Cherry, M. P. Mortelliti, T. Burke-Wolin, and M. S. Wolin. 1991. Inhibition of coronary artery superoxide dismutase attenuates endothelium-dependent and independent nitrovasodilator relaxation. Circ. Res. 69:601-608

36. Devlin, R. G., C. S. Lin, R. J. Pepper, and H. Dougherty. 1981. Evaluation 
of free radical scavengers in studies of lymphocyte mediated cytolysis. Immunopharmacology. 3:147-151.

37. Salin, M. L., and J. M. McCord. 1974. Superoxide dismutase in polymorphonuclear leukocytes. J. Clin. Invest. 54:1005-1009.

38. Misra, H. P., and I. Fridovich. 1977. Superoxide dismutase: a photochemical augmentation assay. Arch. Biochem. Biophys. 181:308-312.

39. Kaduce, T. L., K. C. Norton, and A. A. Spector. 1983. A rapid, isocratic method for phospholipid separation by high-performance liquid chromatography. J. Lipid Res. 24:1398-1403.

40. Palinski, W., M. E. Rosenfeld, S. Ylä-Herttuala, G. C.. Gurtner, S. S. Socher, S. W. Butler, S. Parthasarathy, T. E. Carew, D. Steinberg, and J. L. Witztum. 1989. Low density lipoprotein undergoes oxidative modification in vivo. Proc. Natl. Acad. Sci. USA. 86:1372-1376.

41. Heinecke, J. W., L. Baker, H. Rosen, and A. Chait. 1986. Superoxide mediated modification of low density lipoprotein by human arterial smooth muscle cells in culture. J. Clin. Invest. 77:757-761.

42. Hiramatsu, K., H. Rosen, J. W. Heinecke, G. Wolfbauer, and A. Chait. 1986. Superoxide initiates oxidation of low density lipoprotein by human monocytes. Arteriosclerosis. 7:55-60.

43. Steinbrecher, U. P. 1988. Role of superoxide in endothelial-cell modification of low-density lipoproteins. Biochem. Biophys. Acta. 959:20-30.

44. Karlsson, K., and S. L. Marklund. 1988. Extracellular superoxide dismutase in the vascular system of mammals. Biochem. J. 255:223-228.

45. Halliwell, B., and J. M. C. Gutteridge. 1989. Free Radicals in Biology and Medicine. 2nd ed. Clarendon Press, Oxford, United Kingdom. p. 111.

46. Gotoh, N., and E. Niki. 1992. Rates of interactions of superoxide with vitamin $\mathrm{E}$, vitamin $\mathrm{C}$, and related compounds as measured by chemiluminescence. Biochem. Biophys. Acta. 1115:201-207.

47. Bridges, A. B., N. A. Scott, and J. J. F. Belch. 1991. Probucol, a superoxide free radical scavenger in vitro. Atherosclerosis. 89:263-265.

48. Verbeuren, T. J., F. H. Jordaens, L. L. Zonnekeyn, C. E. VanHove, M. C. Coene, and A. G. Herman. 1986. Effect of hypercholesterolemia on vascular reactivity in the rabbit. Circ. Res. 58:553-564.

49. Ragazzi, E., A. Chinellato, M. De Biasi, L. Pandolfo, M. Proscocimi, F. Norido, L. Caparrotta, and G. Fassina. 1989. Endothelium-dependent relaxation, cholesterol content and high energy matabolite balance in Watanabe hyperlipemic rabbit aorta. Atherosclerosis. 80:125-134.

50. Kritchevsky, D., H. K. Kirn, and S. A. Tepper. 1971. Influence of 4,4(isopropylidenedithio)bis(2,6-di-t-butylphenol)(DH-581) on experimental atherosclerosis in rabbits. Proc. Soc. Exp. Biol. Med. 136:1216-1221.

51. Carew, T. E., D. C. Schwenke, and D. Steinberg. 1987. Antiatherogenic effect of probucol unrelated to its hypocholesterolemic effect: evidence that antioxidants in vivo can selectively inhibit low density lipoprotein degradation in macrophage-rich fatty streaks and slow the progression of atherosclerosis in the Watanabe heritable hyperlipidemic rabbit. Proc. Natl. Acad. Sci. USA. 84:77257729.

52. Ohara, Y., T. E. Peterson, H. S. Sayegh, and D. G. Harrison. 1993. Dietary treatment of hypercholesterolemia normalizes endothelial superoxide production. Circulation. 88:I-467a (Abstr.)

53. Daugherty, A., B. S. Zweifel, and G. Schonfeld. 1989. Probucol attenuates the development of aortic atherosclerosis in cholesterol-fed rabbits. Br. J. Pharmacol. 98:612-618.

54. Steinbrecher, U. P., S. Parthasarathy, D. S. Leake, J. L. Witztum, and D. Steinberg. 1984. Modification of low density lipoprotein by endothelial cells involves lipid peroxidation and degradation of low density lipoprotein phospholipids. Proc. Natl. Acad. Sci. USA. 81:3883-3887.

55. Esterbauer, H., J. Gebicki, H. Puhl, and G. Jürgens. 1992. The role of lipid peroxidation and antioxidants in oxidative modification of LDL. Free Radical Biol. \& Med. 13:341-390.

56. Witztum, J. L., and D. Steinberg. 1991. Role of oxidized low density lipoprotein in atherogenesis. J. Clin. Invest. 88:1785-1792.

57. Halliwell, B. 1989. Current status review: free radicals, reactive oxygen species and human disease: a critical evaluation with special reference to atherosclerosis. Br. J. Exp. Pathol. 70:737-757.

58. Flavahan, N. A. 1992. Atherosclerosis or lipoprotein-induced endothelial dysfunction: potential mechanisms underlying reduction in EDRF/nitric oxide activity. Circulation. 85:1927-1938.

59. Barnhart, R. L., S. J. Busch, and R. L. Jackson. 1989. Concentrationdependent antioxidant activity of probucol in low density lipoproteins in vitro: probucol degradation precedes lipoprotein oxidant. J. Lipid Res. 30:1703-1710.

60. Lynch, S. M., and B. Frei. 1993. Mechanisms of copper-and iron-dependent oxidative modification of human low-density lipoprotein. J. Lipid Res. 34:1745-1753.

61. Smith, C., M. J. Mitchinson, O. I. Aruoma, and B. Halliwell. 1992 Stimulation of lipid peroxidation and hydroxyl radical generation by the contents of human atherosclerotic lesions. Biochem. J. 286:901-905.

62. Huie, R. E., and S. Padmaja. 1993. The reaction of NO with superoxide. Free Radical Res. Commun. 18:195-199.

63. Halliwell, B., and J. M. C. Gutteridge. 1989. Free Radicals in Biology and Medicine. 2nd ed. Clarendon Press, Oxford, United Kingdom. p. 108.

64. Kugiyama, K., M. Ohgushi, S. Sugiyama, T. Murohara, K. Fukunaga, E. Miyamoto, and H. Yasue. 1992. Lysophosphatidylcholine inhibits surface receptor-mediated intracellular signals in endothelial cells by a pathway involving protein kinase C activation. Circ. Res. 71:1422-1428.

65. Parthasarathy, S. 1992. Evidence for an additional intracellular site of action of probucol in the prevention of oxidative modification of low density lipoprotein. Use of a new water-soluble probucol derivative. J. Clin. Invest. 89:1618-1621.

66. Navab, M., S. S. Imes, S. Y. Hama, G. P. Hough, L. A. Ross, R. W. Bork A. J. Valente, J. A. Berliner, D. C. Drinkwater, H. Laks, and A. M. Fogelman. 1991. Monocyte transmigration induced by modification of low density lipoprotein in cocultures of human aortic wall cells is due to induction of monocyte chemotactic protein 1 synthesis and is abolished by high density lipoprotein. J. Clin. Invest. 88:2039-2046. 